\title{
CARACTERIZAÇÃO DO AMBIENTE DE TRABALHO EM UMA COOPERATIVA DE RECICLAGEM
}

\author{
Eduardo Chierrito de ARRUDA ${ }^{1}$ \\ Bruna Mayara de Lima CIBOTTO \\ Me. Carlos Alberto Cury HARFUCH ${ }^{3}$
}

Lidiane Santos NAKAIE ${ }^{4}$

Edison SCHMIDT FILHO 5

Rute Grossi MILANI ${ }^{6}$

\begin{abstract}
${ }^{1}$ Mestrando do Programa de Pós-Graduação em Tecnologias Limpas - PPGTL do Centro Universitário de Maringá (UNICESUMAR).

${ }^{2}$ Mestranda do Programa de Pós-Graduação em Tecnologias Limpas - PPGTL do Centro Universitário Cesumar (UNICESUMAR).

${ }^{3}$ Mestrando do Programa de Pós-Graduação em Tecnologias Limpas - PPGTL do Centro Universitário de Maringá (UNICESUMAR).

${ }^{4}$ Mestranda do Programa de Pós-Graduação em Tecnologias Limpas - PPGTL do Centro Universitário de Maringá (UNICESUMAR).

${ }^{5}$ Docente do Programa de Pós-Graduação em Tecnologias Limpas - PPGTL e Coordenador do Curso de Agronomia do Centro Universitário de Maringá (UNICESUMAR).

${ }^{6}$ Docente do Programa de Pós-Graduação em Tecnologias Limpas - PPGTL e do Programa de Pós-Graduação em Promoção da Saúde - PPGPS, pesquisadora do Instituto Cesumar de Ciências Tecnologia e Informação (ICETI), pelo Centro Universitário de Maringá (UNICESUMAR).
\end{abstract}

Recebido em: 20/12/2016 - Aprovado em: 15/08/2017 - Disponibilizado em: 30/12/2017

\begin{abstract}
RESUMO:
As cooperativas de materiais recicláveis constituem uma das soluções encontradas mediante a crescente produção de resíduos sólidos. Nessas cooperativas, os catadores realizam o recolhimento e reaproveitamento dos resíduos sólidos. O papel dessas cooperativas é cada vez mais importante uma vez que a produção de resíduos é cada vez maior e resulta no acúmulo desses materiais em centros urbanos. Porém, a realidade nacional é que esses trabalhadores vivem em situações precárias. $\mathrm{O}$ objetivo deste trabalho foi caracterizar o ambiente de trabalho em uma cooperativa de reciclagem a fim de identificar os principais problemas ambientais presentes e inferir possíveis impactos na qualidade de vida dos trabalhadores. A técnica de observação foi utilizada para avaliar cinco itens relacionados aos fatores ambientais e de qualidade de vida do Manual de Impactos Ambientais, tais como degradação do valor econômico do local, colaboração da comunidade na separação dos resíduos, presença de materiais perfurantes ou contaminantes e a produção de odores. Diante disso, foi constatada a precariedade do ambiente de trabalho, com a presença de vetores transmissores de doença, fortes odores, materiais cortantes e possível contaminação do solo. Com isso, podemos concluir que apesar dos esforços do poder público no desenvolvimento das cooperativas, existem carências a serem supridas na gestão compartilhada dos resíduos, reduzindo impactos diretos na atividade profissional dos catadores.
\end{abstract}

Palavras-chave: Bem estar. Saúde humana. Catadores de lixo. Gerenciamento de resíduos. Coleta seletiva. 


\title{
WORK ENVIRONMENT CHARACTERIZATION ON A RECYCLING COOPERATIVE
}

\begin{abstract}
:
The recyclable materials cooperatives are one of the solutions found by increasing production of solid waste. In these cooperatives, the collectors perform the collection and recycling of solid waste. The role of these unions is increasingly important since waste production is increasing and results in the accumulation of these materials in urban centers. However, the national reality is that these workers live in precarious situations. The aim of this study was to characterize the working environment in a recycling cooperative in order to identify the main environ mental problems and inferring quality of life of members. The observation technique was used to evaluate five items related to environmental factors and quality of life Environmental Impact Manual, such as: degradation of the economic local value, community collaboration in waste separation, the presence of perforating material for contaminants and production odors. Thus, it was found the precarious mess of the working environment, with the presence of disease vectors transmitters, strong odors, sharps and possible oil contamination. Hence, we can conclude that despite the government's efforts in the development of cooperatives, there are needs to be met in the shared management of waste, reducing direct impact on the professional activity of collectors.
\end{abstract}

Keywords: Well-being. Humanhealth. Garbagecollectors. Waste management. Selectivecollect.

\section{INTRODUÇÃO}

A produção de resíduos sólidos urbanos (RSU) é considerada um desafio eminente aos gestores públicos. No atual cenário nacional o manejo de resíduos sólidos possui um papel de destaque na mídia, seja por repetitivos problemas no despejo de efluentes ou nas enchentes em grandes centros urbanos. A má gestão dos RSU resulta no acúmulo de materiais em centros urbanos ou bairros, terrenos vazios ou córregos, o que propicia a proliferação de doenças, como a Dengue, e as enchentes e erosões em centros urbanos (JACOBI; BESEN， 2011; RIBEIRO; KITRON, 2016).

Desde 1960 o movimento ecologista ganha força em âmbitos como o poder público; a academia e a força popular, principalmente pela preocupação ambiental emergente sobre os impactos da sociedade de consumo (PINHEIROet al., 2014). A partir da conferência Rio-92 o tema da disposição dos RSUpassou a ser investigado exaustivamente, com ênfase em propostas que articulam o poder público e o privado para a sustentabilidade no ciclo de consumo, o que levou à criação de políticas, técnicas e tecnologias de manejo e tratamentos dos resíduos, a fim de reduzir impactos à natureza (MINISTÉRIO DO MEIO AMBIENTE, 2005).

Entre as principais medidas de manejo dos RSU, as cooperativas de reciclagem possibilitam uma atividade socioeconômica importante. Os cooperados são catadores de materiais recicláveis que recolhem os resíduos sólidos recicláveis e reaproveitáveis, como papelão, alumínio, plástico e vidro, e são responsáveis pela maior parcela de 
materiais recicláveis coletados no Brasil (LOBATO; LIMA, 2011). A profissão dos Catadores foi reconhecida na Classificação Brasileira de Ocupações (CBO) pela Portaria n. ${ }^{o}$ 397, de 9 de outubro de 2002, do Ministério do Trabalho, sob o Código n. ${ }^{\circ}$ 5.192-05 (MINISTÉRIO PÚBLICO DE MINAS GERAIS, 2013).

Segundo os dados apresentados no manual dePolítica Nacional de Resíduos Sólidos(2012) existe em média 500 mil catadores de materiais recicláveis no Brasil, dos quais apenas 10\% atuam em alguma organização coletiva. Segundo informações disponibilizadas pelo Ministério Público de Minas Gerais (2013),o país que gera cerca de 180 mil toneladas de resíduos sólidos por dia, das quais 58 mil são recicláveis. Desse total, os catadores contribuem para que sejam reciclados, 98\% das latinhas de alumínio, $56 \%$ do plástico, $48 \%$ do papel e $47 \%$ do vidro. Em sua maioria,os trabalhadores não utilizam qualquer tipo de proteção e estão diariamente expostos a diversos tipos de riscos ocupacionais e enfermidades (SILVA; NOVAIS, 2014).

$$
\text { É importante ressaltar que a }
$$
categoria dos catadores reciclados apresenta heterogeneidade entre seus integrantes. Muitos catadores exercem esse tipo de atividade em tempo integral por muitos anos, desde a infância. Muitos passam a exercer essa profissão após a perda do emprego e dificuldade em encontrar outra atividade. Existem os catadores que seguem uma rotina de trabalho diária, enquanto outros desenvolvem essa atividade em horários menos regulares. A maioria dos catadores não possui outra fonte de renda, fator agravado pela falta de escolaridade(SILVA; GOES; ALVAREZ, 2013; SILVA; NOVAIS, 2014).

A organização do trabalho também ocorre de maneira homogênea e diversificada. Existem aqueles que trabalham sozinhos ou em família e aqueles que se associam a alguma cooperativa de reciclados, com o objetivo de unir forças por meio do trabalho coletivo. Em relação a sua residência, há aqueles que possuem um local fixo para residir e outros que vivem em locais de grande vulnerabilidade física, como as vias públicas. (SILVA; GOES; ALVAREZ, 2013).

A atividade laboral dos catadores implicana exposição a materiais com possível toxicidade e condições de trabalho ainda desfavoráveis, assim como a falta de logística em suas atividades, por exemplo, o acesso restrito a caminhões, obrigandoos a rejeitar coletas grandes. Existe nessa esfera um "desamparo estrutural" por parte do poder público (BAPTISTA, 2015, p. 21). 
Além das perspectivas estruturais e de toxicidade do trabalho com materiais recicláveis, os vieses econômicos e sociais infligem níveis desiguais de competição no mercado e preconceito diante da atividade, tais aspectos estão diretamente relacionados com o bem-estar dos trabalhadores com resíduos sólidos, ou seja, o possível impacto ambiental vinculado a esses fatores externos está diretamente associado à atividade realizada.

O trabalho e suas vicissitudes estão diretamente relacionadas à qualidade de vida dos catadores. Este é um conceito amplamente difundido na área da saúde e está associado às vivências compartilhadas em um determinado ambiente. As questões ambientais influenciam na qualidade de vida, em níveis positivos e negativos (PEREIRA et al., 2016).A partir dessas articulações este estudo busca caracterizar o ambiente de trabalho em uma cooperativa de reciclagem a fim de identificar os principais problemas ambientais que podem apresentar impactos sobre a qualidade de vida dos cooperados.

\section{METODOLOGIA}

O trabalho foi realizado a partir de observações in loco em uma cooperativa de reciclagem, por três pesquisadores, a partir de uma análise sistematizada em um check-list desenvolvido e adaptado pelos autores com base no Manual de Impactos Ambientais (DIAS, 1999).

A observação ocorreuem uma cooperativa de reciclagem, com apoio do poder público, no interior do Estado do Paraná-Brasil, nos meses de maio e junho de 2016. O trabalho realizado na cooperativa abrange em média 70 toneladas de materiais recicláveis por mês, representando cerca de $5 \%$ do material produzido pela cidade. Os números de trabalhadores na cooperativa representam 24 pessoas, do sexo masculino e feminino, e o local é constituído de um refeitório e barracões para os processos de coleta e separação, prensamento e pesagem e resíduos não reaproveitados.

$\mathrm{O}$ instrumento utilizado consiste em um check-listsistematizado pelos autores meio base no Manual de Impactos Ambientais (DIAS, 1999):

1. Disposição dos resíduos sólidos em locais inadequados: Obstrução de galerias de drenagem; Fatores que indicam a degradação do valor econômico do local; Fatores que indicam a redução do valor da terra e do entorno; Indícios de queimada ao céu aberto ou disposição incorreta no solo; Indícios de proliferação de vetores transmissores de doenças;

2. Separação dos resíduos sólidos pelos moradores: Colaboração dos moradores ou geradores dos resíduos sólidos; Resíduos sólidos pré-separados na 
chegada do material; Limpeza dos resíduos sólidos;

3. Impactos direcionados ao meio ambiente (entorno): Fatores que indicam a geração de odores; Fatores que indicam a geração de poeira; Fatores que indicam o desperdício de água;

4. Impactos referentes à condição de trabalho: Fatores que indicam a presença de Resíduos de saúde ou lixo hospitalar; Uso de Equipamentos de Segurança pelos trabalhadores; Condições específicas para uma cozinha adequada ao ambiente de trabalho;

5. Impactos ambientais específicos: Fatores que indicam possível contaminação das águas subterrâneas; Fatores que indicam possível contaminação do solo; Fatores que indicam possível contaminação por vias aéreas.

O presente estudo foi adaptado de um instrumento de pesquisa padronizado, considerados itens relevantes ao indicar fatores ambientais e possíveis incidências sob a qualidade de vida. A conduta da pesquisa deu-se mediante o esclarecimento dos objetivos e a garantia de sigilo e de participação ao responsável direto da cooperativa (Termo de uso de imagem) e do Munícipio (Termo de consentimento do Local). O tempo médio de coleta de dados foi de aproximadamente duas horas.

Os resultados foram analisados a partir do material levantado no check-list e registrado por imagens para discussão. A seguir serão apresentados os resultados e os principais pontos a serem discutidos em três categorias específicas: A iminência de impactos ambientais na receptação e armazenamento de matéria prima; $\mathrm{O}$ problema da qualidade da separação de resíduos sólidos pela comunidade e as propostas de intervenção pública.

\section{RESULTADOS E DISCUSSÃO}

Os catadores de materiais recicláveis foram os agentes que mais sofreram transformações com a implementação da Política Nacional de Resíduos Sólidos (2012) e suas novas diretrizes. Pode-se classificar essas transformações em esferas específicasda identidade pessoal; da atividade laboral e da perspectiva econômica. A identidade pessoal é uma das esferas mais importantes para o trabalhador, uma vez que, conforme Baptista (2015), a terminologia “desempregados" perde força no decorrer dos anos e a sociedade passa a compreender essa categoria de um ponto de vista emancipatório e com um potencial econômico e produtivo singular, no entanto ainda existe uma premissa higienista e assistencialista, características que não condiz com a prática da sustentabilidade.

As cooperativas de reciclagem desenvolvem um trabalho singular com 
uma viabilidade econômica em potencial, assim como outras atividades exercem um impacto no ambiente. A relação pessoa e ambiente consiste em uma dialética em que o desenvolvimento sustentável está diretamente associado à qualidade de vida.

\subsection{A iminência de impactos ambientais}

na receptação e armazenamento de matéria prima

Segundo os itens analisados os impactos ambientais na atividade da cooperativa são minimizados em virtude da logística empregada, associando a separação da matéria prima com a coleta direta dos resíduos dos domicílios, por transportes do município, o que reduz a perda de matéria prima. O fluxo de entrada dos materiais é realizado por caminhões terceirizados pelo poder público, que descarregam os resíduos na cooperativa, como apresentado na figura 1.

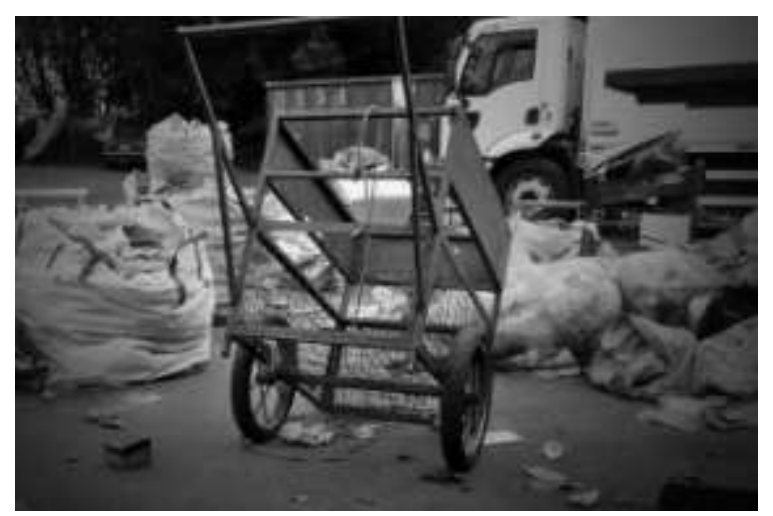

Figura 1 -Entrada de materiais na cooperativa

As disposições dos resíduos sólidos nas cooperativas são feitas em ambientes cobertos e organizados em montantes dispostos diretamente no solo, sem um piso protetor ou canaletas para facilitar a separação de restos residuais. Por meio de rachaduras no concreto, esse contaminante é filtrado pelo solo, que gera risco de contaminação do solo ou das águas subterrâneas (figura 2). Essa exposição também exerce influência na degradação do valor econômico do local, não agravantes no caso da cooperativa analisada, uma vez que são propriedades públicas.Também não foram constatados materiais dispostos em galerias de drenagem e nem fatores que indiquem queimadas.

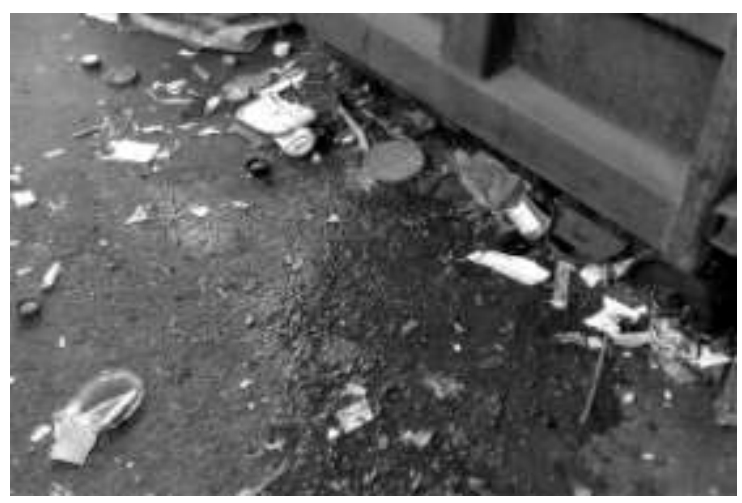

Figura 2 - Iminência de impactos ambientais ao solo e águas subterrâneas na cooperativa

Em relação à proliferação de doenças é possível observar alguns riscos associados à disposição dos materiais e à baixa qualidade ou limpeza que esses chegam ao local, muitos materiais são receptados em condição úmida, com insetos epequenos animais (ratos). $\mathrm{O}$ 
acúmulo de materiais com possíveis vetores gera risco de transmissão de doenças, apesar desses serem utilizados rapidamente e com equipamentos de segurança pelos cooperados. A possibilidade de impactos ambientais descritas acimas, não atingem apenas os trabalhadores, mas também a comunidade.

\subsection{O problema da qualidade da} separação de resíduos sólidos pela comunidade

Os principais impactos observados nesse ambiente estão relacionados à forma que a matéria prima chega aos trabalhadores. O manejo de resíduos sólidos domésticos ou empresariais realizado pela população se dá de forma inadequada, geralmente associado à má limpeza dos materiais, resíduos eletrônicos, inserção de lixo hospitalar e materiais cortantes, esses são associados à condição de trabalho dos cooperados e concomitantemente infligem sobre a qualidade de vida e no meio ambiente (RIBEIRO, et al. 2014). A figura 3 ilustra a incidência de restos orgânicos e materiais não recicláveis coletados em um montante, fato que três de tamanho aproximado foram observados durante a pesquisa.

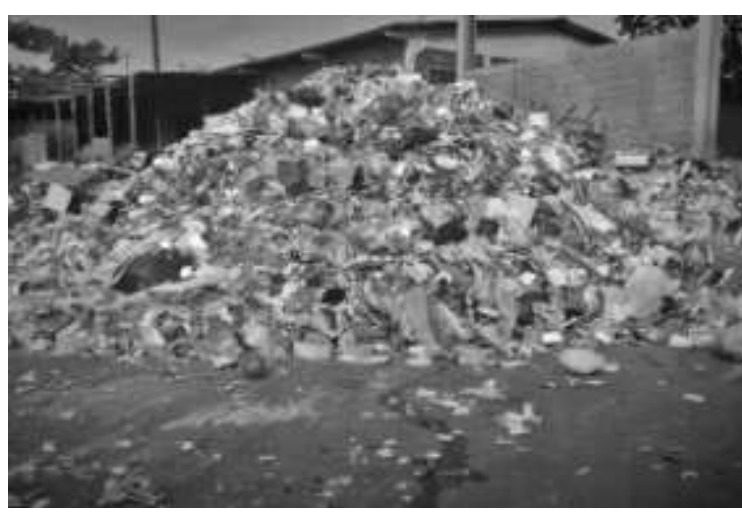

Figura 3 - Resíduos não recicláveis dispostos na cooperativa

A falta de limpeza dos materiais gera um forte odor associado aos possíveis problemas de saúde, como a renite e complicações respiratórias. A separação ineficiente dos cidadãos resulta na perda de matéria prima e tempo de trabalho, que podem ser evitadas com metidas aparentemente simples, como a lavagem de embalagens.

A desinformação da comunidade referente a separação dos resíduos sólidos resulta na confusão de como descartar o lixo eletrônico, como indica a figura 4. Dada a sua composição singular com metais pesados e componentes contaminantes esses resíduos devem ser direcionados para coletas específicas (GIARETTA et al.,2010). 


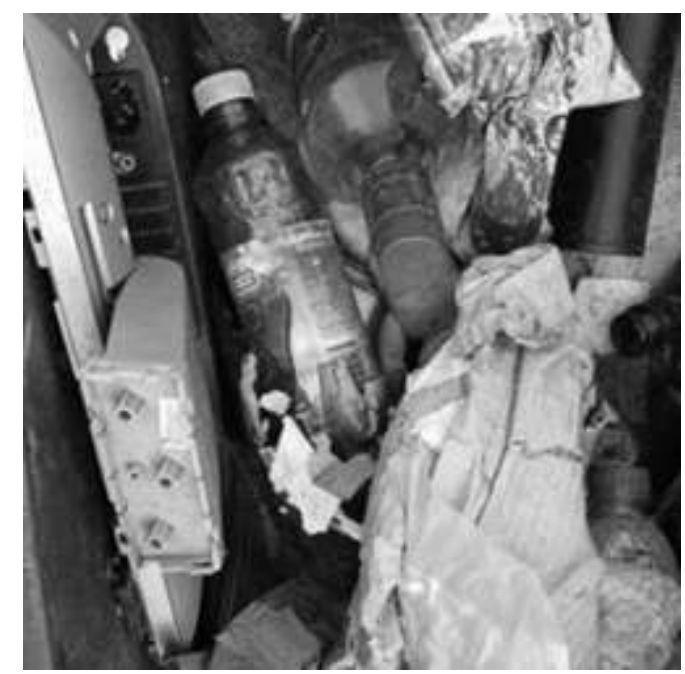

Figura 4 - Incidência de Lixo Eletrônico em meio ao lixo comum

Para a expansão da reciclagem, Demajorovic e Lima (2013) enfatizam que a população urbana deve se responsabilizar pela produção de seus resíduos, uma vez que produzem grandes quantidades de resíduos sólidos. O apoio da comunidade é uma via possível e deve ser incentivada por programas de sensibilização ambiental e campanhas de conscientização sobre a separação de resíduos sólidos, incluindo a limpeza e os pontos de coleta para o lixo eletrônico.

O fato da logística de coleta ser terceirizada pelo poder público infere em impactos positivos e negativos, uma vez que a perda de materiais no decorrer do trajeto é limitada em um meio de transporte adequado, porém os cooperados são alienados do processo de coleta e não possuem a oportunidade de interagirem com a comunidade para sugerir mudanças na separação dos resíduos de forma adequada, ou condutas apropriadas para tratar materiais cortantes ou contaminantes.

Os cooperados utilizam equipamento de segurança no local de trabalho, porém tais equipamentos evitam acidentes pequenos, diferente dos possíveis acidentes propiciados pelos materiais coletados. Segundo a observação dos pesquisadores resíduos com materiais cortantes e contaminantes (seringas e agulhas) são frequentemente encontrados, como indicado na figura 5.

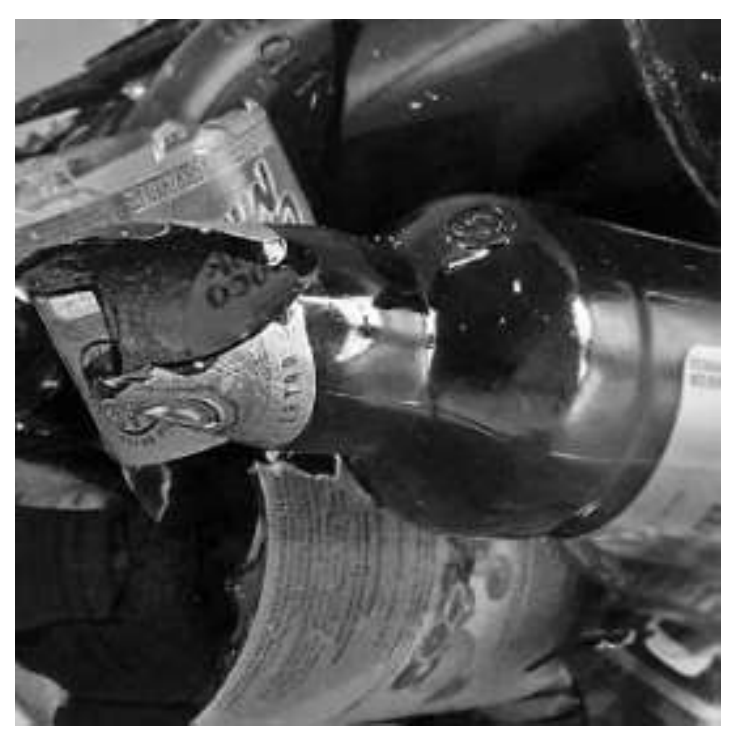

Figura 5 - Resíduos cortantes encontrados na cooperativa

Magera (2003), explica a rotina de trabalho dos catadores de reciclados como uma atividade exaustiva e com força de tração humana. O mapeamento do processo de seleção dos RSU desenvolvido por Lobato e Lima (2010) aponta a carência de equipamentos básicos, tanto 
para o processo, quanto para a triagem, caracterizada como um processo manual e crucial para o decorrer das atividades. Fatos que foram constados na observação e que influenciam negativamente a qualidade de vida dos trabalhadores.

Da perspectiva econômica as cooperativas ou associações têm por objetivo a prestação de serviços à sociedade e devem contar com aparelhos e tecnologias que respondam as suas demandas para que os valores gerados possuam mais valia (BAPTISTA, 2015; DEMAJOROVIC, et al. 2014). O investimento público é crucial para o desenvolvimento das cooperativas, o que reflete diretamente na qualidade de vida dos trabalhadores.

\subsection{Propostas de intervenção pública}

A destinação dos resíduos sólidos domésticos é amplamente complexa, dado ao aumento populacional e ao rápido desenvolvimento industrial. Os avanços no ritmo de consumo e a diversidade de materiais consumidos refletem no esgotamento de aterros e lixões,e evidenciam o nível de desinformação da população e a falta de atitudes ecológicas (HIRAMA; SILVA, 2010).

Uma das propostas de intervenção pública são as campanhas educativas, com foco na sensibilização ambiental da população,orientando para a separação dos resíduos, assim como a devida limpeza das embalagens.Outra melhoria é a aquisição de maquinários específicos, como picotadoras de papéis ou plástico, e meios de transporte para evitar a sobrecarga humana, o que previne acidentes de trabalho.

A reformulação da estrutura tributária e os incentivos fiscais são propostas cruciais para a valorização econômica da atividade, uma vez que o modelo atual não estimula o consumo de materiais recicláveis (BAPTISTA, 2015; DEMAJOROVIC, et al. 2014). Uma sugestão é a cobrança de taxas proporcionais aos resíduos gerados como prática de sensibilização ambiental e minimização do consumo (JACOBI; BESEN, 2011).

O Plano Nacional de Resíduos Sólidos (2012) apresenta políticas públicas que foram incorporadas para promover a inclusão social e econômica dos trabalhadores em diversas cidades do País. Entre elas destacam-se o incentivo às cooperativas, a regulamentação da atividade profissional, o fortalecimentodo programa pró-catador e propostas de pagamentos por serviços ambientais urbanos. Algumas medidas podem ser implantadas para facilitar a gestão compartilhada de resíduos sólidos:

1) Criar uma sede central que represente as cooperativas, com o objetivo 
de facilitar: a gestão burocrática; os empréstimos; a negociação do que se produz com o mercado e a profissionalização dos recursos humanos, com o objetivo de desenvolver adequada competência de gestão para toda a cadeia produtiva do setor;

2) Estruturar de maneira adequada as cooperativas, em parcerias com o poder público ou empresas privadas, oferecendo financiamento a custo zero, de máquinas e equipamentos, assim como a parceria com instituições de ensino e pesquisa em novas tecnologias;

3) Facilitar a voz política do cooperado no desenvolvimento de campanhas ou políticas públicas, juntamente com o poder municipal, estadual e federal, sociedade local e regional, ONG's e outras instituições;

4) Promover a logística reversa de modo que a população possa levar esses resíduos, devidamente limpos e selecionados, para locais previamente escolhidos, e receba bônus pela devolução dos materiais;

5) Integrar toda a população no esforço comum de diminuição dos resíduos e sua correta gestão;

6) Investir na educação ambiental transformadora, ou seja integrar uma perspectiva social e emancipatória na reflexão escolar, por meio de revelar as causas e consequências no trato com resíduos sólidos, no ensino infantil, fundamental, médio e superior, e consequentemente promover atitudes de cidadania e ética.

Estes apontamentos e sugestões devem considerar a participação de catadores em programas de educação e sensibilização ambiental e garantir $o$ acesso a resíduos coletados seletivamente. Essas ações favorecem o cuidado ao meio ambiente e a promoção de qualidade de vida dos trabalhadores, respaldados por direitos e deveres que valorizem sua profissão e atuação na sociedade.

\section{CONSIDERAÇÕES FINAIS}

A presente pesquisa permitiu explanar sobre as condições de trabalho das cooperativas de reciclagem, que incidem na qualidade de vida e ao meio ambiente. É fato que esforços dopoder público têm sido significativos em prol do desenvolvimento e manutenção das cooperativas, no entanto, há muito o que se fazer, sobretudo no que se refere à profissionalização dos cooperados.

A falta de participação popular na separação de resíduos sólidos, resulta em impactos diretos à saúde humana, como materiais cortantes ou hospitalares depositados com os resíduos sólidos. Tal realidade sinaliza a necessidade da formulação de políticas públicas e privadas, que promovem a qualidade de 
vida e de trabalho dos trabalhadores em suas cooperativas.Deve-se delinearações adequadas e competentes em relação às questões ambientais, através do envolvimento da sociedade em diversos setores públicos,apoiados por secretárias específicas, como a saúde, a educação e o meio ambiente. $\mathrm{O}$ trabalho interdisciplinar apoiado pela população visa integrar as responsabilidades sobre a produção de resíduos sólidos. A gestão pública e a população ao compartilharem suas experiências garantem a possiblidade de melhora da qualidade de vida e da saúde humana, assim como a preservação ambiental.

\section{REFERÊNCIAS}

BAPTISTA, Vinícius Ferreira. As políticas públicas de coleta seletiva no município do Rio de Janeiro: onde e como estão as cooperativas de catadores de materiais recicláveis?, Revista de Administração Pública, v. 49, n. 1, p. 141164, 2015.

GIARETTA, Juliana Barbosa Zuquer; TANIGUSHI, Daniel Gouveia; SERGENT, Marcela Tashiro; VASCONCELLOS, Maria da Penha; GÜNTHER, Wanda Maria Risso. Habitsrelatedtothe post-consumptiondiscardof mobile phonesandtheirbatterieswithinanacademiccom munity. Saúde e Sociedade, v. 19, n. 3, p. 674-684, 2010.

DEMAJOROVIC, Jacques; LIMA, Márcia. Cadeia de Reciclagem: um olhar para os catadores. São Paulo: Sesc, 2013. 155 p.

DEMAJOROVIC, J.et al. Integrando empresas e cooperativas de catadores em fluxos reversos de resíduos sólidos pósconsumo: o caso Vira-
Lata. Cadernos EBAPE, v.12, p.513-532, 2014.

DIAS, Manoel. Manual de impactos ambientais: orientações básicas sobre aspectos ambientais de atividades produtivas. Fortaleza: Embrapa (1999). 297 p. Disponível em:

<http://www.infoteca.cnptia.embrapa.br/handl e/doc/928622>. Acesso em: mai. 2016.

HIRAMA, Ângela Megumi; DA SILVA, Sidinei Silvério. Coleta seletiva de lixo: uma análise da experiência do município de Maringá-PR. Revista Tecnológica, v. 18, n. 1, p. 11-23, 2010.

JACOBI, Pedro Roberto; BESEN, Gina Rizpah. Gestão de resíduos sólidos em São Paulo: desafios da sustentabilidade. Estudos Avançados, v. 25, n. 71, p. 135-158, 2011.

LOBATO, Kelly Carla Dias; LIMA, Josiane Palma. Modelagem conceitual como procedimento de apoio para melhorias em processos de seleção de materiais recicláveis, in Encontro Nacional de Engenharia de Produção, 32, 2011, Belo Horizonte, resumo... Belo Horizonte, ABEPRO, 2011, p.11. Disponível em: <http://www.abepro.org.br/biblioteca/enegep2 011_tn_wic_135_861_19078.pdf>. Acesso em: 06 jun. 2016.

MAGERA, Márcio. Os empresários do lixo: um paradoxo da modernidade-análise interdisciplinar das cooperativas de reciclagem de lixo. Campinas, Átomo, 2003.

\section{MINISTÉRIO PÚBLICO DE MINAS}

GERAIS. O Catadoré legal: Um guia na luta pelos direitos dos Catadores de Materiais Recicláveis, 2013. Disponível em: http://www.coopcentabc.org.br/documentos/C ARTILHA_CATADORES.pdf. Acesso em: 06 mai. 2016.

\section{MINISTÉRIO DO MEIO AMBIENTE.}

Agenda 21 brasileira. 2005. Disponível em $<$ http://www.mma.gov.br/responsabilidadesocioambiental/agenda-21/agenda-21brasileira>. Acesso em: 21 set. 2015.

PEREIRA, Denise Nunes; MEDEIROS, Ana Paula Ribeiro; SANTOS, Kelly da Conceição 
Pereira; GONÇALVES, Helaine Cristine; TENÓRIO, Renata Sousa. Conservação ambiental e qualidade de vida: uma análise qualitativa do parque estadual do Utinga, Belém. Cadernos de Agroecologia, Recife, v.10, n.3, p., 2015.

PINHEIRO, Leonardo Victor de Sá et al.

Comportamento, crenças e valores ambientais: uma análise dos fatores que podem influenciar atitudes pró-ambientais de futuros administradores. Revista de Gestão Social e Ambiental - RGSA, São Paulo, v.8, n.1, p.89104, 2014.

PNRS - Política nacional de resíduos sólidos:

Lei no 12.305/10. 2010,2. ed. - Brasília:

Câmara dos Deputados, Edições Câmara, 2012.

RIBEIRO, Guilherme Sousa.; KITRON, Uriel. Zika virus pandemic: a human and public health crisis. Rev. Soc. Bras. Med. Trop., Uberaba, v.49, n.1, p.1-3, 2016.

RIBEIRO, Luiz Carlos de Santana et al. Aspectos econômicos e ambientais da reciclagem: um estudo exploratório nas cooperativas de catadores de material reciclável do Estado do Rio de Janeiro. Nova Economia, v. 24, n. 1, p. 191-214, 2014.

SILVA, Sandro Pereira; GOES, Fernanda Lira; ALVAREZ, Albino Rodrigues. Situação Social das Catadoras e dos Catadores de Material Reciclável e Reutilizável. IPEA Instituto de Pesquisa Econômica Aplicada, 2013.

SILVA, Lanairada; NOVAIS, Bruna Prado de. Dos sistemas de disposições de resíduos sólidos na sociedade pós-consumo: uma análise da Lei 12.305/2010 e seus reflexos nas cooperativas de material reciclável no município de Maringá/PR. Planeta Amazônia: Revista Internacional de Direito Ambiental e Políticas Públicas, n. 5, p. 5970, 2014 